\title{
Treatment Changes, Healthcare Resource Utilization, and Costs Among Patients with Symptomatic Obstructive Hypertrophic Cardiomyopathy: A Claims Database Study
}

\author{
Anjali T. Owens (D) - Megan B. Sutton · Wei Gao · Jennifer T. Fine • \\ Jipan Xie $\cdot$ Srihari S. Naidu $\cdot$ Nihar R. Desai
}

Received: November 19, 2021 / Accepted: February 4, 2022 / Published online: March 1, 2022

(C) The Author(s) 2022

\begin{abstract}
Introduction: There is limited evidence on therapies for obstructive hypertrophic cardiomyopathy (HCM), and data regarding treatment patterns and cost are scarce. This study assessed treatment patterns and economic outcomes in patients with symptomatic obstructive HCM.
\end{abstract}

\footnotetext{
A. T. Owens $(\square)$

Center for Inherited Cardiovascular Disease, Perelman Center for Advanced Medicine, University of Pennsylvania Perelman School of Medicine, 11th Floor South Tower, 3400 Civic Center Blvd, Philadelphia, PA 19014, USA

e-mail: anjali.owens@pennmedicine.upenn.edu

M. B. Sutton · J. T. Fine

Myokardia, Inc., a wholly owned subsidiary of Bristol Myers Squibb, Brisbane, CA, USA

W. Gao

Analysis Group, Inc., Boston, MA, USA

J. Xie

Analysis Group, Inc., Los Angeles, CA, USA

S. S. Naidu

Department of Cardiology, Westchester Medical Center, Westchester Medical Center Health

Network, New York Medical College, Valhalla, NY, USA

\section{N. R. Desai}

Section of Cardiovascular Medicine, Department of Medicine, Yale University School of Medicine, New Haven, CT, USA
}

Methods: Adults with symptomatic obstructive HCM as per study design and treated with pharmacotherapies [beta blockers (BBs), calcium channel blockers (CCBs), BB + CCB, or disopyramide] or procedures (septal reduction therapy, heart transplantation, implantable cardioverter-defibrillator, and pacemaker implantation) were identified from the IBM ${ }^{\circledR}$ MarketScan ${ }^{\circledR}$ Commercial and Medicare Supplemental database (January 2009-March 2019). Patients had 12-month continuous eligibility before and after (study period) treatment initiation (index treatment). Healthcare resource utilization (HRU), costs, and treatment changes were assessed.

Results: Of the 4883 patients included in the analysis, 85\% received pharmacotherapies (BB 52.5\%; CCB 11.7\%; BB + CCB 17.7\%; disopyramide $2.4 \%$ ) and $15.7 \%$ underwent procedures. During the study period, 38,34 , and $100 \%$ of all patients had $\geq 1$ inpatient stay, emergency room (ER) visit, and outpatient visit, respectively; mean total healthcare costs were US $\$ 53,053$. Patients undergoing procedures had the highest HRU and costs across groups. Among patients receiving pharmacotherapies, HRU was lowest with BBs and highest with disopyramide. Treatment changes were observed in $43.8 \%$ of patients receiving pharmacotherapies.

Conclusions: Patients experienced high rates of treatment changes, and the economic burden associated with symptomatic obstructive HCM 
increased as therapy escalated. More effective therapies are needed to stabilize or decrease the economic burden of obstructive HCM.

Keywords: Healthcare costs; Healthcare resource utilization; Obstructive hypertrophic cardiomyopathy; Treatment change

\section{Key Summary Points}

Why carry out this study?

There is limited evidence on therapies for obstructive hypertrophic cardiomyopathy (HCM), and data regarding treatment patterns and cost are scarce.

\section{What was learned from the study?}

The study suggests substantial economic burden associated with existing treatments of symptomatic obstructive HCM, particularly among patients whose symptoms cannot be effectively controlled by beta blocker or calcium channel blocker monotherapy and require escalating therapy.

The high rate of treatment change might be due to suboptimal outcomes and/or dissatisfaction with current therapy.

Novel effective therapies are needed to improve patient outcomes and reduce the burden of symptomatic obstructive HCM, especially as symptoms and disease progress.

\section{INTRODUCTION}

Hypertrophic cardiomyopathy (HCM) is a primary myocardial disorder defined by left ventricular (LV) hypertrophy that cannot be explained by another cardiac or systemic disease [1, 2]. HCM can be caused by pathogenic variation in genes encoding the cardiac sarcomere. HCM has two subtypes: nonobstructive HCM and obstructive HCM. In obstructive HCM, the thickened septum may cause a dynamic narrowing that can block or reduce the blood flow from the left ventricle to the aorta [LV outflow tract (LVOT)]. The estimated prevalence of $\mathrm{HCM}$ is $0.2-0.5 \%$ of the adult population globally [1-7]. Obstructive HCM, clinically defined as a resting or provoked peak dynamic LV outflow gradient of at least $30 \mathrm{mmHg}$, occurs in up to approximately $70 \%$ of patients with HCM [8].

Two previous studies reported the proportion of patients with symptoms in obstructive HCM populations $[9,10]$. Maron et al. reported that $61 \%$ of patients with obstructive HCM were symptomatic, as indicated by having a New York Heart Association (NYHA) class greater than I, whereas Lu et al. reported that $49 \%$ of patients with obstructive HCM were symptomatic $[9,10]$. Common symptoms include fatigue, chest pain, dyspnea, palpitations, dizziness, and syncope [11, 12], which may substantially impair quality of life, including physical and mental well-being [13-16]. Furthermore, patients with obstructive $\mathrm{HCM}$ are likely to experience increased risks of downstream cardiovascular conditions, such as heart failure (HF), atrial fibrillation/flutter, and sudden cardiac death [4]. In addition to the disease burden experienced by patients, symptomatic obstructive HCM is associated with a considerable economic burden. A large US claims study estimated that the annual healthcare costs of symptomatic obstructive HCM was $>$ US\$43,000 per patient (2019 US dollars) and that $38 \%$ of patients experienced at least one hospitalization during the first year of diagnosis [17]. These results translated to US $\$ 36,000$ higher annual healthcare costs and substantial increases in healthcare resource utilization (HRU) for patients with symptomatic obstructive HCM compared with matched controls without cardiomyopathy.

There are no approved pharmacotherapies that address the underlying pathophysiology of the disease. Beta blockers (BBs) or non-dihydropyridine calcium channel blockers (CCBs) are recommended in US guidelines as the firstline pharmacological treatment to control obstructive HCM-related symptoms [1, 2]. Combination therapy with a $\mathrm{BB}$ and a $\mathrm{CCB}$ $(\mathrm{BB}+\mathrm{CCB})$ can be used in patients who have 
concomitant conditions such as hypertension, or if the side-effect profile of one agent at high dose is intolerable [2]. The addition of disopyramide is recommended as an advanced pharmacotherapy if severe symptomatic obstruction remains despite treatment with BBs and/or CCBs, or when the disease is complicated by atrial fibrillation $[1,4]$. However, there is limited evidence supporting the effectiveness of these pharmacotherapies in obstructive HCM, and there is some evidence that disopyramide may lose its efficacy over time [5]. Septal reduction therapy (SRT) with surgical septal myectomy or catheter-based alcohol septal ablation is recommended for relieving LVOT obstruction in eligible patients who remain severely symptomatic despite guideline-directed management and therapy [2]. The success of SRT largely depends on the local expertise and experience of the treatment center [18-20]. In addition, placement of an implantable cardioverter-defibrillator is recommended in patients with a history of cardiac arrest or with sustained ventricular tachycardia and should be offered to adult patients with HCM and at least one risk factor for sudden cardiac death [2]. Furthermore, intentional right ventricular pacing may be considered in patients with obstructive HCM who have drug-refractory symptoms and who are not eligible for alcohol septal ablation or septal myectomy [21]. Finally, heart transplantation assessment is indicated in patients with advanced-stage disease and no alternative treatment options [2].

The lack of response to pharmacotherapies in some patients with symptomatic obstructive HCM may lead to invasive procedures that in turn might result in increased HRU and cost. Existing studies investigating the effectiveness of obstructive HCM treatments have generally focused on the outcomes associated with a single treatment or procedure. For example, results from a study among patients with HCM undergoing SRT (septal myectomy and alcohol septal ablation) indicated that the median length of inpatient stay was 7-8 days for septal myectomy and 3-4 days for alcohol septal ablation, with median hospitalization costs of US\$146,778-162,203 for septal myectomy and US\$62,340-84,041 for alcohol septal ablation, depending on the hospital volume [18]. However, there is limited understanding of the burden associated with the overall treatment landscape in symptomatic obstructive HCM, including pharmacotherapies and surgical, interventional, or medical procedures.

The present study aimed to fill this knowledge gap by generating real-world evidence on HRU, healthcare costs, and treatment changes among patients with symptomatic obstructive HCM who were treated with either pharmacotherapies or procedures.

\section{METHODS}

\section{Study Design and Data Source}

This retrospective observational study used healthcare claims data from the IBM ${ }^{\circledR}$ MarketScan ${ }^{\circledR}$ Commercial and Medicare Supplemental database from January 2009 to March 2019. This database includes the medical and pharmacy claims of insured employees and their dependents covered by health benefits programs of large employers across the USA, as well as Medicare-eligible retirees with employerprovided Medicare Supplemental plans [22]. Available data include demographics, comorbidities, claims, clinical visits, and costs (assessed from the commercial payer's perspective). Institutional Review Board approval was not required as the patient data were de-identified. This article is based on information from an existing database and does not contain any new studies with human participants or animals performed by any of the authors.

\section{Sample Selection}

Patients with obstructive HCM were identified as those meeting one of the following criteria: (1) at least one medical claim with an International Classification of Diseases, Ninth/Tenth Revision, Clinical Modification (ICD-9/10-CM) diagnosis code for obstructive HCM (ICD-9-CM: 425.11; ICD-10-CM: I42.1) and another medical claim with a diagnosis code for HCM (ICD-9CM: 425.1; ICD-10-CM: I42.1 or I42.2) that 
were at least 30 days apart; or (2) at least one medical claim with a diagnosis code for HCM and another claim on a different date for SRT, including alcohol septal ablation and septal myectomy. Patients were excluded if they had a claim with a diagnosis code for Fabry disease or amyloidosis at any time.

To be considered as "treated," patients were required to receive at least one treatment for obstructive HCM on or after the first observed HCM diagnosis or undergo SRT at any time. In addition to SRT, the treatments considered in this study included BB, CCB, disopyramide, implantable cardioverter-defibrillator, heart transplant, and pacemaker (without bradyarrhythmia). The initiation date of a pharmacotherapy or the date of a procedure was defined as a potential index date. Patients were required to be aged $\geq 18$ years at the index date and have 12 months of continuous eligibility before and after the index date (baseline and study periods, respectively, with a total evaluation time of 24 months). The first date that satisfied the study criteria was defined as the index date (Fig. 1a). Treatment initiated on the index date was defined as index treatment.

In this study, the definition of symptomatic obstructive HCM was based on claims data or coding and not on NYHA class or clinical definitions. Patients with obstructive HCM were classified as symptomatic if they met the following criteria: (1) had a medical claim for fatigue, chest pain, syncope, dyspnea, or palpitations during the baseline period; (2) had a medical claim for $\mathrm{HF}$ at any time prior to the index date; or (3) received pacemaker implantation or SRT as the index treatment. Patients who underwent pacemaker implantation or an SRT procedure during the baseline period but not as the index treatment were not considered symptomatic, because their symptoms might be controlled after treatment, and were excluded from the study.

Treated patients with symptomatic obstructive HCM were classified into five groups based on their index treatment: $\mathrm{BB}$ alone (without $\mathrm{CCB}$ or disopyramide), $\mathrm{CCB}$ alone (without $\mathrm{BB}$ or disopyramide), BB + CCB (without disopyramide), disopyramide (monotherapy or combination therapy with $\mathrm{BB}$ and/or CCB), and procedure (SRT, implantable cardioverter-defibrillator implantation, heart transplantation, or pacemaker implantation). Patients could be simultaneously classified in a pharmacotherapy group and the procedure group.

\section{Patient Characteristics and Study Outcomes}

Patient demographics and comorbidities, including all components of the Charlson Comorbidity Index $[23,24]$ and selected cardiac comorbidities, were assessed during the baseline period. All-cause HRU, including inpatient stays, outpatient visits, and emergency room (ER) visits, was assessed during the study period. For each type of HRU, the proportion of patients with any HRU, as well as the frequency of HRU, was measured. The number of inpatient days per patient was also estimated. All-cause healthcare costs, including pharmacy and medical care costs, were assessed during the study period. Costs were based on reimbursements paid by commercial health plans and did not include co-pays or other cost-sharing arrangements. All costs were inflated to 2020 US dollars using the Medical Care Component of the Consumer Price Index by the US Bureau of Labor Statistics. Patient characteristics, HRU, and healthcare costs were assessed in the overall population of patients with symptomatic obstructive HCM and stratified by index treatment group.

For the pharmacotherapy groups, the times from the index date to the first SRT, HCM-related inpatient admission, and HCM-related ER visit, as well as changes to the index treatment, were assessed. HCM-related inpatient admissions and ER visits were identified as claims associated with a diagnosis for HCM regardless of the primary reason for admission. Treatment changes included discontinuation (stopping a treatment for at least 60 days), switching, and augmentation. Treatment switching was defined as: (1) initiating a new class of pharmacological treatment at least 30 days after the index date with an overlap in prescription fills between the index treatment and the new treatment of $<30$ days; or (2) stopping at least 

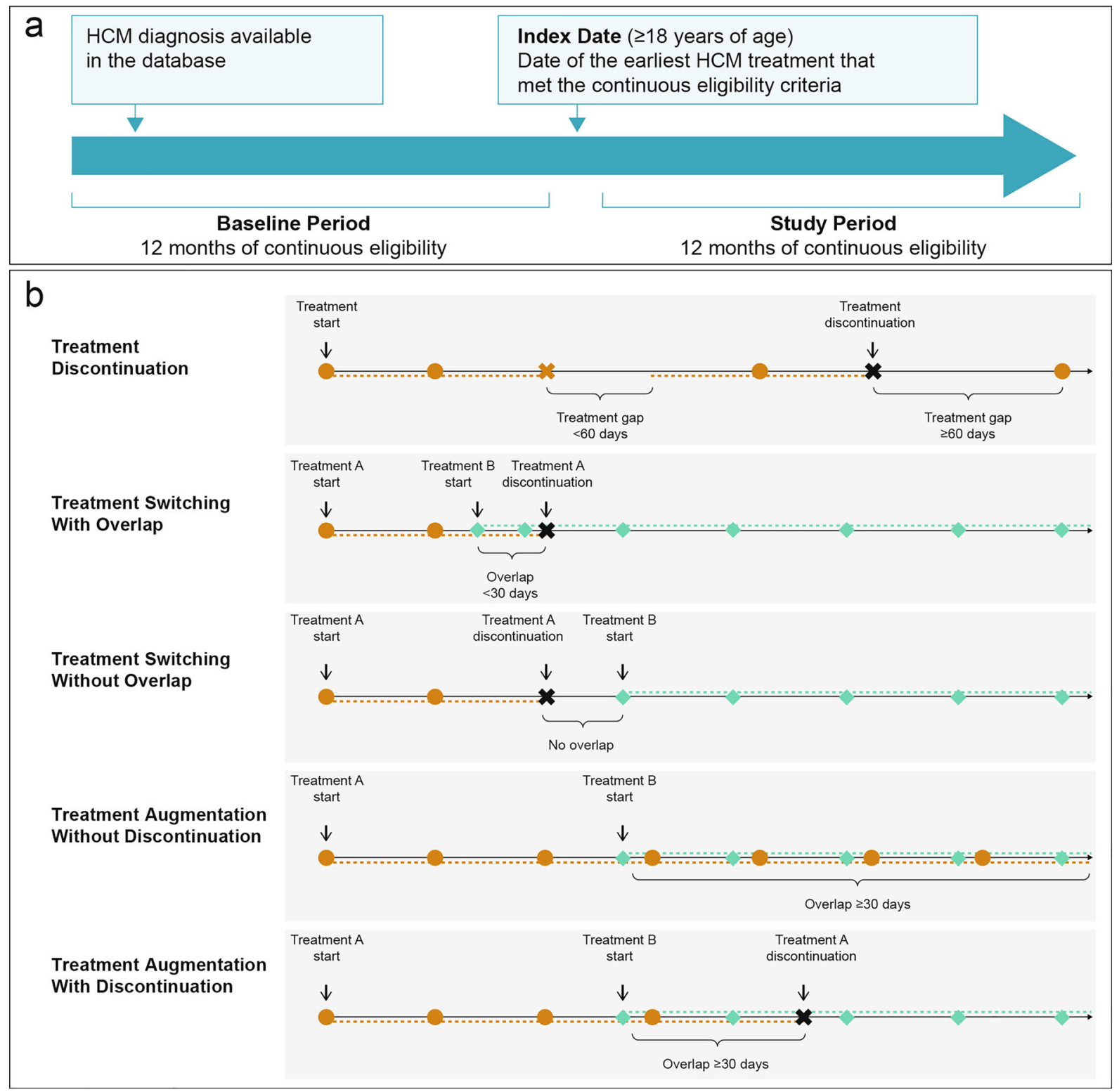

Fig. 1 Definition of index date (a) and treatment changes (b). HCM Hypertrophic cardiomyopathy

one treatment in a combination therapy for at least 60 days while the rest of the treatments in the combination therapy continued for at least 30 days (Fig. 1b). Treatment augmentation was defined as the initiation of a new treatment at least 30 days after the index date with an overlap in prescription fills between the index treatment and the new treatment of at least 30 days.

\section{Statistical Methods}

Continuous variables were described by means and standard deviations (SDs), and categorical variables were described by counts and proportions. Time-to-event outcomes were estimated using Kaplan-Meier analysis, with event rates reported at different time points. For the analysis of treatment discontinuation, patients without an event were censored at 60 days prior 
to the end of the study period. For the analysis of switching and augmentation, patients without an event were censored at the date when a new treatment was initiated within 30 days of the end of the study period or at the end of the study period if no new treatment was detected. For the analysis of time to first SRT, HCM-related inpatient admission, and HCM-related ER visit, patients without an event were censored at the end of the study period. Analyses were performed using SAS version 9.4 (SAS Institute, Cary, NC, USA) and R-3.6.3 software (R Foundation for Statistical Computing, Vienna, Austria).

\section{RESULTS}

\section{Patient Population}

Of 7847 treated patients with obstructive HCM identified in the claims database (January 2009-March 2019), 4883 (62.2\%) were classified as symptomatic per our study definition (Fig. 2). The most common obstructive HCM symptom was dyspnea $(54.8 \%)$, followed by fatigue (26.4\%), palpitations (26.3\%), syncope (15.6\%), and chest pain (12.0\%). Among the study sample, $35.6 \%$ of patients had a claims code for HF prior to the index date and $8.5 \%$ underwent SRT or pacemaker implantation at the index date (Fig. 3). The most common pharmacotherapy index treatment was BB $[n=3431$ $(70.2 \%)]$ as monotherapy $[n=2565(52.5 \%)]$ or combination therapy $[n=866(17.7 \%)]$, followed by CCB $(n=1457 \quad(29.4 \%)]$ as monotherapy $[n=571(11.7 \%)]$ or combination therapy $[n=866(17.7 \%)]$ and disopyramide $[n=119(2.4 \%)]$. In total, 765 patients $(15.7 \%)$ underwent procedures as the index treatment: implantable cardioverter-defibrillator implantation [412 (53.9\%)], SRT [364 (47.6\%)], pacemaker implantation [51 (6.7\%)], and heart transplantation [11 (1.4\%)] (Fig. 4).

The demographics and baseline comorbidities of the cohort of patients classified as having symptomatic obstructive HCM, grouped by index treatment, are summarized in Table 1 . In this cohort, $47.6 \%$ were women, the mean (SD) age was $58( \pm 14)$ years, and the mean (SD) Charlson Comorbidity Index at baseline was 1.8 $( \pm 1.7)$. The proportion of women was numerically lower in the procedure (39.7\%) and BB alone $(46.4 \%)$ groups than in the other groups (52.7-54.6\%). Hypertension was the most common cardiovascular comorbidity (69.4\%),

\begin{tabular}{|c|c|}
\hline \multirow{2}{*}{$\begin{array}{l}\text { Patients with at least one HCM diagnosis and at least one of the } \\
\text { following events } \\
\text { (1) Another HCM diagnosis at least } 30 \text { days apart } \\
\text { (2) At least one SRT procedure on a different date } \\
\qquad N=36728\end{array}$} & \multirow{8}{*}{$\begin{array}{l}\text { Symptomatic } \\
\text { obstructive HCM } \\
\quad N=4883(62.2 \%) \\
\text { Symptoms during the } \\
\text { 12-month baseline period } \\
\text { - Fatigue } \\
\text { - Chest pain } \\
\text { - Syncope/near syncope } \\
\text { - Dyspnea } \\
\text { - Palpitations } \\
\text { Conditions any time before } \\
\text { the index date } \\
\text { - Heart failure } \\
\text { Procedures on the } \\
\text { index date } \\
\text { - Pacemaker implantation } \\
\text { (without bradyarrhythmia } \\
\text { before the index date) } \\
\text { - SRT }\end{array}$} \\
\hline & \\
\hline$\downarrow$ & \\
\hline $\begin{array}{l}\text { Patients received SRT at any time or a selected treatment } \\
\text { on or after the first HCM diagnosis observed in the data } \\
\qquad N=26759\end{array}$ & \\
\hline$\downarrow$ & \\
\hline $\begin{array}{l}\text { At least } 12 \text { months of continuous eligibility before and after } \\
\text { the index date; } 18 \text { years of age or older at the index date } \\
\qquad N=10882\end{array}$ & \\
\hline$\nabla$ & \\
\hline $\begin{array}{l}\text { At least one obstructive } \mathrm{HCM} \text { diagnosis or at least one SRT procedure } \\
\qquad \boldsymbol{N = 7 8 4 7}\end{array}$ & \\
\hline
\end{tabular}

Fig. 2 Sample selection. ${ }^{a}$ Index date is the initiation date of a pharmacotherapy or date of procedure for HCM. SRT Septal reduction therapy 


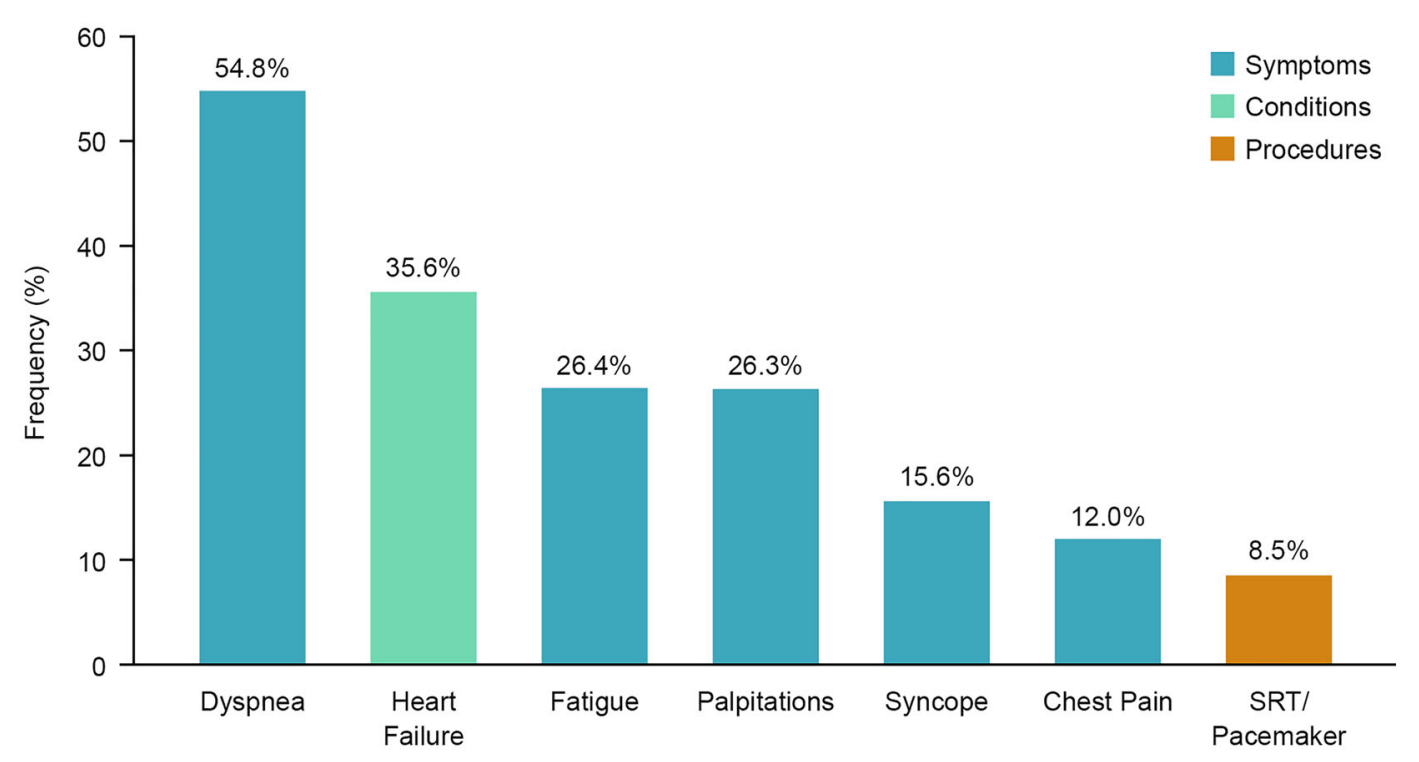

Fig. 3 Frequency of symptoms, conditions, and procedures in treated patients with symptomatic obstructive hypertrophic cardiomyopathy at any time before the start of the study

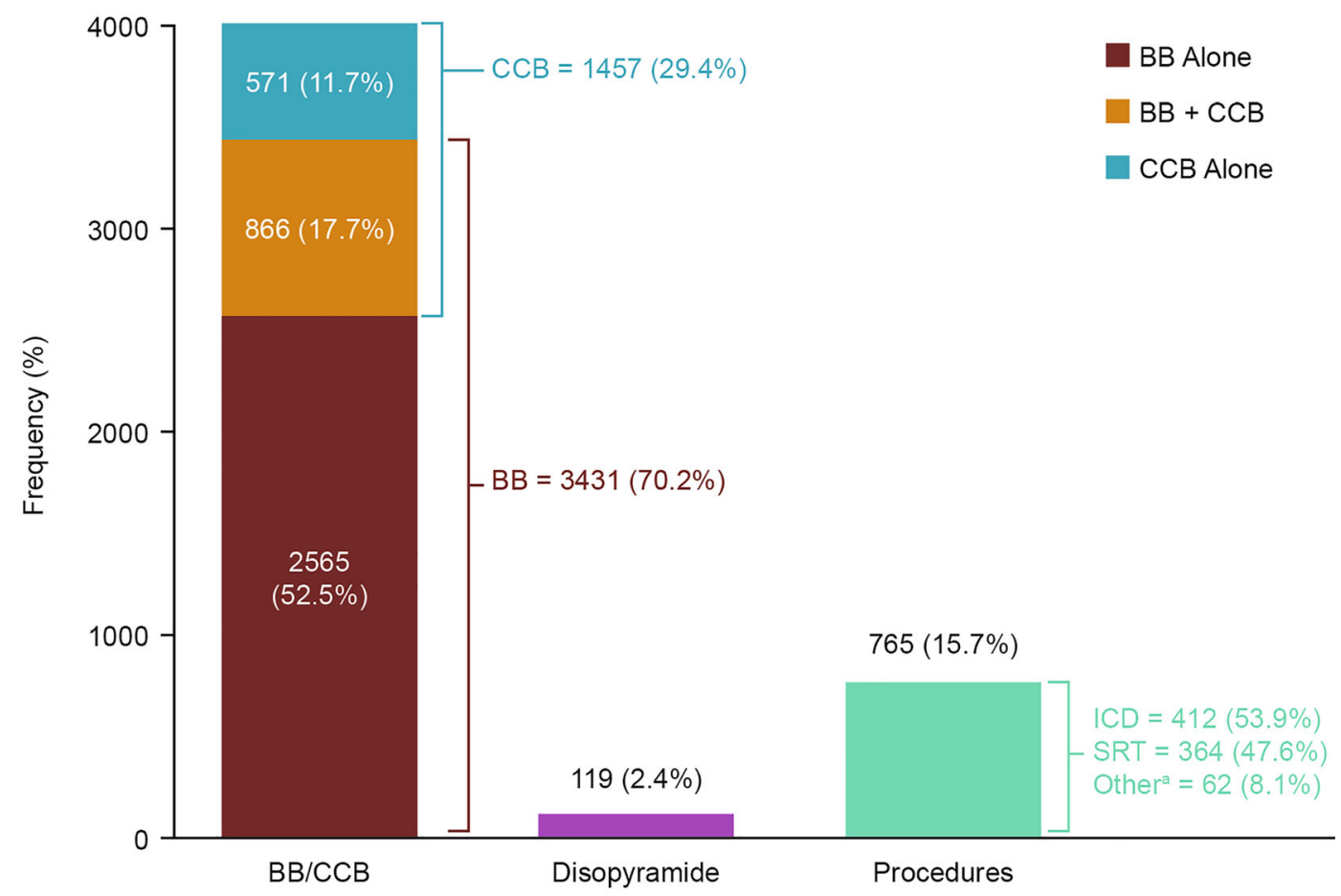

Fig. 4 Distribution of index treatment among treated patients with symptomatic obstructive hypertrophic cardiomyopathy. " "Other" included heart transplantation and

followed by congestive HF (51.9\%), coronary artery disease (38.1\%), HF (26.2\%), atrial pacemaker implantation. $B B$ Beta blocker, $C C B$ calcium channel blocker, ICD implantable cardioverter-defibrillator

fibrillation/flutter (24.1\%), and bradyarrhythmia $(18.2 \%)$. 
Table 1 Demographics and baseline clinical characteristics

\begin{tabular}{|c|c|c|c|c|c|c|}
\hline \multirow{2}{*}{$\begin{array}{l}\text { Demographics and baseline } \\
\text { clinical characteristics }\end{array}$} & \multirow{2}{*}{$\begin{array}{l}\text { Symptomatic } \\
\text { obstructive } \\
\text { HCM }^{\mathbf{a}} \\
(N=4883)\end{array}$} & \multicolumn{5}{|c|}{ Index treatment groups } \\
\hline & & $\begin{array}{l}\text { BB alone } \\
(n=2565)\end{array}$ & $\begin{array}{l}\text { CCB alone } \\
(n=571)\end{array}$ & $\begin{array}{l}\mathrm{BB}+\mathrm{CCB} \\
(n=866)\end{array}$ & $\begin{array}{l}\text { Disopyramide } \\
(n=119)\end{array}$ & $\begin{array}{l}\text { Procedure } \\
(n=765)\end{array}$ \\
\hline \multicolumn{7}{|l|}{ Demographics } \\
\hline $\begin{array}{l}\text { Age at the index date } \\
\text { (years), mean } \pm S D\end{array}$ & $58 \pm 14$ & $58 \pm 15$ & $60 \pm 14$ & $62 \pm 13$ & $57 \pm 12$ & $55 \pm 13$ \\
\hline Female sex, $n(\%)$ & $2324(47.6)$ & $1191(46.4)$ & $310(54.3)$ & $456(52.7)$ & $65(54.6)$ & $304(39.7)$ \\
\hline \multicolumn{7}{|l|}{ Symptoms, $n(\%)$} \\
\hline Dyspnea & $2675(54.8)$ & $1382(53.9)$ & $341(59.7)$ & $517(59.7)$ & $73(61.3)$ & $364(47.6)$ \\
\hline Fatigue & $1289(26.4)$ & $684(26.7)$ & $171(29.9)$ & $234(27.0)$ & $33(27.7)$ & $168(22.0)$ \\
\hline Palpitations & $1285(26.3)$ & $701(27.3)$ & $149(26.1)$ & $214(24.7)$ & $35(29.4)$ & $186(24.3)$ \\
\hline Syncope & $763(15.6)$ & $410(16.0)$ & $82(14.4)$ & $110(12.7)$ & $17(14.3)$ & $145(19.0)$ \\
\hline Chest pain & $588(12.0)$ & $320(12.5)$ & $71(12.4)$ & $129(14.9)$ & $9(7.6)$ & $59(7.7)$ \\
\hline \multicolumn{7}{|c|}{ Cardiovascular comorbidities, $n(\%)$} \\
\hline Hypertension & $3387(69.4)$ & $1686(65.7)$ & $430(75.3)$ & $738(85.2)$ & $75(63.0)$ & $460(60.1)$ \\
\hline Coronary artery disease & $1859(38.1)$ & $953(37.2)$ & $176(30.8)$ & $362(41.8)$ & $43(36.1)$ & $326(42.6)$ \\
\hline Heart failure & $1280(26.2)$ & $672(26.2)$ & $100(17.5)$ & $247(28.5)$ & $29(24.4)$ & $233(30.5)$ \\
\hline Atrial fibrillation/flutter & $1178(24.1)$ & $521(20.3)$ & $102(17.9)$ & $226(26.1)$ & $49(41.2)$ & $282(36.9)$ \\
\hline Bradyarrhythmia & $887(18.2)$ & $416(16.2)$ & $94(16.5)$ & $153(17.7)$ & $21(17.6)$ & $205(26.8)$ \\
\hline \multicolumn{7}{|l|}{ Charlson comorbidity index } \\
\hline Mean $\pm S D$ & $1.8 \pm 1.7$ & $1.7 \pm 1.7$ & $1.6 \pm 1.7$ & $2.0 \pm 1.7$ & $1.8 \pm 1.5$ & $1.9 \pm 1.5$ \\
\hline Median (IQR) & $2.0(0,3.0)$ & $2.0(0,2.0)$ & $2.0(0,3.0)$ & $2.0(1.0,13.0)$ & $2.0(0,2.0)$ & $2.0(0,3.0)$ \\
\hline \multicolumn{7}{|c|}{ Charlson comorbidity index components, $n$ (\%) } \\
\hline Congestive heart failure & $2536(51.9)$ & $1292(50.4)$ & $222(38.9)$ & $469(54.2)$ & $71(59.7)$ & $483(63.1)$ \\
\hline Chronic pulmonary disease & $1125(23.0)$ & $540(21.1)$ & $186(32.6)$ & $227(26.2)$ & $22(18.5)$ & $152(19.9)$ \\
\hline $\begin{array}{l}\text { Diabetes without chronic } \\
\text { complications }\end{array}$ & $807(16.5)$ & $418(16.3)$ & $84(14.7)$ & $175(20.2)$ & $16(13.4)$ & $114(14.9)$ \\
\hline Peripheral vascular disease & $655(13.4)$ & $331(12.9)$ & $65(11.4)$ & $144(16.6)$ & $14(11.8)$ & $101(13.2)$ \\
\hline Cerebrovascular disease & $628(12.9)$ & $302(11.8)$ & $75(13.1)$ & $136(15.7)$ & $14(11.8)$ & $101(13.2)$ \\
\hline Myocardial infarction & $436(8.9)$ & $224(8.7)$ & $37(6.5)$ & $84(9.7)$ & $11(9.2)$ & $80(10.5)$ \\
\hline Renal disease & $375(7.7)$ & $164(6.4)$ & $43(7.5)$ & $107(12.4)$ & $8(6.7)$ & $54(7.1)$ \\
\hline $\begin{array}{l}\text { Any malignancy, including } \\
\text { leukemia and lymphoma }\end{array}$ & $353(7.2)$ & $173(6.7)$ & $50(8.8)$ & $81(9.4)$ & $8(6.7)$ & $41(5.4)$ \\
\hline
\end{tabular}


Table 1 continued

\begin{tabular}{|c|c|c|c|c|c|c|}
\hline \multirow{2}{*}{$\begin{array}{l}\text { Demographics and baseline } \\
\text { clinical characteristics }\end{array}$} & \multirow{2}{*}{$\begin{array}{l}\text { Symptomatic } \\
\text { obstructive } \\
\text { HCM }^{\mathrm{a}} \\
(N=4883)\end{array}$} & \multicolumn{5}{|c|}{ Index treatment groups } \\
\hline & & $\begin{array}{l}\text { BB alone } \\
(n=2565)\end{array}$ & $\begin{array}{l}\text { CCB alone } \\
(n=571)\end{array}$ & $\begin{array}{l}\text { BB }+C C B \\
(n=866)\end{array}$ & $\begin{array}{l}\text { Disopyramide } \\
(n=119)\end{array}$ & $\begin{array}{l}\text { Procedure } \\
(n=765)\end{array}$ \\
\hline $\begin{array}{l}\text { Diabetes with chronic } \\
\text { complications }\end{array}$ & $293(6.0)$ & $137(5.3)$ & $32(5.6)$ & $77(8.9)$ & $5(4.2)$ & $42(5.5)$ \\
\hline Mild liver disease & $263(5.4)$ & $150(5.8)$ & $31(5.4)$ & $43(5.0)$ & $9(7.6)$ & $30(3.9)$ \\
\hline Rheumatological disease & $160(3.3)$ & $81(3.2)$ & $13(2.3)$ & $41(4.7)$ & $2(1.7)$ & $23(3.0)$ \\
\hline Peptic ulcer disease & $78(1.6)$ & $39(1.5)$ & $8(1.4)$ & $18(2.1)$ & $5(4.2)$ & $8(1.0)$ \\
\hline Hemiplegia or paraplegia & $42(0.9)$ & $17(0.7)$ & $5(0.9)$ & $13(1.5)$ & $1(0.8)$ & $6(0.8)$ \\
\hline Dementia & $42(0.9)$ & $25(1.0)$ & $3(0.5)$ & $9(1.0)$ & $1(0.8)$ & $4(0.5)$ \\
\hline Metastatic solid tumor & $36(0.7)$ & $20(0.8)$ & $4(0.7)$ & $9(1.0)$ & $0(0.0)$ & $3(0.4)$ \\
\hline $\begin{array}{l}\text { Moderate or severe liver } \\
\text { disease }\end{array}$ & $15(0.3)$ & $13(0.5)$ & $0(0.0)$ & $2(0.2)$ & $0(0.0)$ & $0(0.0)$ \\
\hline AIDS/HIV & $8(0.2)$ & $5(0.2)$ & $2(0.4)$ & $0(0.0)$ & $0(0.0)$ & $1(0.1)$ \\
\hline \multicolumn{7}{|l|}{ Procedure, $n(\%)$} \\
\hline $\begin{array}{l}\text { Implantable cardioverter- } \\
\text { defibrillator }\end{array}$ & $125(2.6)$ & $59(2.3)$ & $6(1.1)$ & $25(2.9)$ & $2(1.7)$ & $33(4.3)$ \\
\hline
\end{tabular}

$A I D S$ Acquired immunodeficiency syndrome, $B B$ beta blocker, $C C B$ calcium channel blocker, $H C M$ hypertrophic cardiomyopathy, $H I V$ human immunodeficiency virus, $I Q R$ interquartile range, $S D$ standard deviation

${ }^{a}$ Patients with obstructive HCM were classified as symptomatic if they met the following criteria: (1) had a medical claim for fatigue, chest pain, syncope, dyspnea, or palpitations during the baseline period; (2) had a medical claim for heart failure at any time prior to the index date; or (3) received pacemaker implantation or septal reduction therapy as the index treatment

\section{Resource Utilization and Healthcare Costs}

HRU and healthcare costs for patients with symptomatic obstructive HCM overall and by index treatment during the study period are summarized in Table 2 and Fig. 5 . Within the study cohort, $37.9 \%$ of patients had at least one inpatient admission; the mean (SD) number of inpatient admissions was $0.6( \pm 1.0)$ per patient, with a mean (SD) of 3.7 ( \pm 11.5$)$ days spent in hospital. The BB group had the lowest number of inpatient admissions per patient [0.4 (SD \pm 0.8$)]$, followed by the CCB [0.5 (SD \pm 1.0)], $\mathrm{BB}+\mathrm{CCB}[0.6$ (SD \pm 1.0$)]$, disopyramide $[0.6(\mathrm{SD} \pm 0.9)]$, and procedure (1.2 $(\mathrm{SD} \pm 1.2)]$ groups. Similarly, the BB group had the lowest number of days in hospital [2.5 $(\mathrm{SD} \pm 7.0)]$, followed by the CCB $[3.2(\mathrm{SD} \pm 10.5)], \mathrm{BB}+$ CCB $[3.4(\mathrm{SD} \pm 9.6)]$, disopyramide $[4.3(\mathrm{SD} \pm$ $12.1)]$, and procedure [8.7 ( $\mathrm{SD} \pm 21.0)]$ groups. In the study cohort, $33.8 \%$ had at least one ER visit; the mean (SD) number of ER visits was 0.7 $( \pm 1.5)$ per patient. The proportion of patients with an ER visit was higher in the disopyramide group $(41.2 \%)$ than in the other index treatment groups (BB + CCB 37.1\%; CCB 35.9\%; procedure $35.2 \%$; BB 31.5\%). The mean number of ER visits per patient was similar across the index treatment groups. Regardless of the index treatment, most patients had an outpatient visit during the study period. In the study cohort, $99.7 \%$ had at least one outpatient visit, with a mean (SD) of $26.5( \pm 23.1)$ outpatient visits per patient. The number of outpatient visits [mean 
Table 2 All-cause healthcare resource utilization during the study period

\begin{tabular}{|c|c|c|c|c|c|c|}
\hline \multirow{2}{*}{$\begin{array}{l}\text { All-cause } \\
\text { healthcare resource } \\
\text { utilization }\end{array}$} & \multirow{2}{*}{$\begin{array}{l}\text { Symptomatic } \\
\text { Obstructive } \\
\text { HCM }^{\mathbf{a}} \\
(N=\mathbf{4 8 8 3})\end{array}$} & \multicolumn{5}{|c|}{ Index treatment groups } \\
\hline & & $\begin{array}{l}\text { BB alone } \\
(n=2565)\end{array}$ & $\begin{array}{l}\text { CCB alone } \\
(n=571)\end{array}$ & $\begin{array}{l}B B+C C B \\
(n=866)\end{array}$ & $\begin{array}{l}\text { Disopyramide } \\
(n=119)\end{array}$ & $\begin{array}{l}\text { Procedure } \\
(n=765)\end{array}$ \\
\hline \multicolumn{7}{|l|}{ All-cause IP admissions } \\
\hline Any IP admission, $n(\%)$ & $1851(37.9)$ & $742(28.9)$ & $175(30.6)$ & $318(36.7)$ & $48(40.3)$ & $569(74.4)$ \\
\hline \multicolumn{7}{|l|}{ Number of IP admissions } \\
\hline Mean $\pm S D$ & $0.6 \pm 1.0$ & $0.4 \pm 0.8$ & $0.5 \pm 1.0$ & $0.6 \pm 1.0$ & $0.6 \pm 0.9$ & $1.2 \pm 1.2$ \\
\hline Median (IQR) & $0(0,1)$ & $0(0,1)$ & $0(0,1)$ & $0(0,1)$ & $0(0,1)$ & $0(0,1)$ \\
\hline \multicolumn{7}{|l|}{ Number of IP days } \\
\hline Mean $\pm S D$ & $3.7 \pm 11.5$ & $2.5 \pm 7.0$ & $3.2 \pm 10.5$ & $3.4 \pm 9.6$ & $4.3 \pm 12.1$ & $8.7 \pm 21.0$ \\
\hline Median (IQR) & $0(0,4)$ & $0(0,2)$ & $0(0,2)$ & $0(0,4)$ & $0(0,4)$ & $0(0,8)$ \\
\hline \multicolumn{7}{|l|}{ All-cause ER visits } \\
\hline Any ER visit, $n(\%)$ & $1651(33.8)$ & $807(31.5)$ & $205(35.9)$ & $321(37.1)$ & $49(41.2)$ & $269(35.2)$ \\
\hline \multicolumn{7}{|l|}{ Number of ER visits } \\
\hline Mean \pm SD & $0.7 \pm 1.5$ & $0.6 \pm 1.5$ & $0.7 \pm 1.3$ & $0.8 \pm 1.5$ & $0.8 \pm 1.5$ & $0.7 \pm 1.6$ \\
\hline Median (IQR) & $0(0,1)$ & $0(0,1)$ & $0(0,1)$ & $0(0,1)$ & $0(0,1)$ & $0(0,1)$ \\
\hline \multicolumn{7}{|l|}{ All-cause OP visits } \\
\hline Any OP visit, $n(\%)$ & $4870(99.7)$ & $2558(99.7)$ & $569(99.6)$ & $865(99.9)$ & $118(99.2)$ & $763(99.7)$ \\
\hline \multicolumn{7}{|l|}{ Number of OP visits } \\
\hline Mean $\pm S D$ & $26.5 \pm 23.1$ & $24.6 \pm 22.0$ & $27.6 \pm 26.3$ & $27.6 \pm 20.8$ & $28.2 \pm 21.6$ & $30.4 \pm 26.1$ \\
\hline Median (IQR) & $21(12,35)$ & $19(11,32)$ & $21(11,38)$ & $22(13,36)$ & $22(11,42)$ & $24(14,39)$ \\
\hline
\end{tabular}

ER Emergency room, $I P$ inpatient, $O P$ outpatient

${ }^{2}$ Patients with obstructive HCM were classified as symptomatic if they met the following criteria: (1) had a medical claim for fatigue, chest pain, syncope, dyspnea, or palpitations during the baseline period; (2) had a medical claim for heart failure at any time prior to the index date; or (3) received pacemaker implantation or septal reduction therapy as the index treatment

(SD)] per patient was highest in the procedure group $[30.4( \pm 26.1)]$, followed by the disopyramide $\quad[28.2 \quad( \pm 21.6)], \quad \mathrm{BB}+\mathrm{CCB} \quad[27.6$ $( \pm 20.8)]$, CCB alone $[27.6( \pm 26.3)]$, and BB alone $[24.6( \pm 22.0)]$ groups.

During the study period, the study cohort incurred US\$53,053 (SD \pm US\$128,016) per patient in healthcare costs. Healthcare costs were primarily driven by inpatient costs, followed by outpatient costs. Across all index treatment groups, total healthcare costs [mean (SD)] per patient were highest for the procedure group [US\$137,260 ( \pm US\$230,218)]; however, among the pharmacotherapy groups, the disopyramide group had the highest total healthcare costs per patient [US\$53,473 ( \pm US\$118,786)]. The remaining treatment groups, including the $\mathrm{BB}, \mathrm{CCB}$, and $\mathrm{BB}+\mathrm{CCB}$ groups, had similar mean (SD) healthcare costs per patient: US\$37,241 ( \pm US\$92,916), 


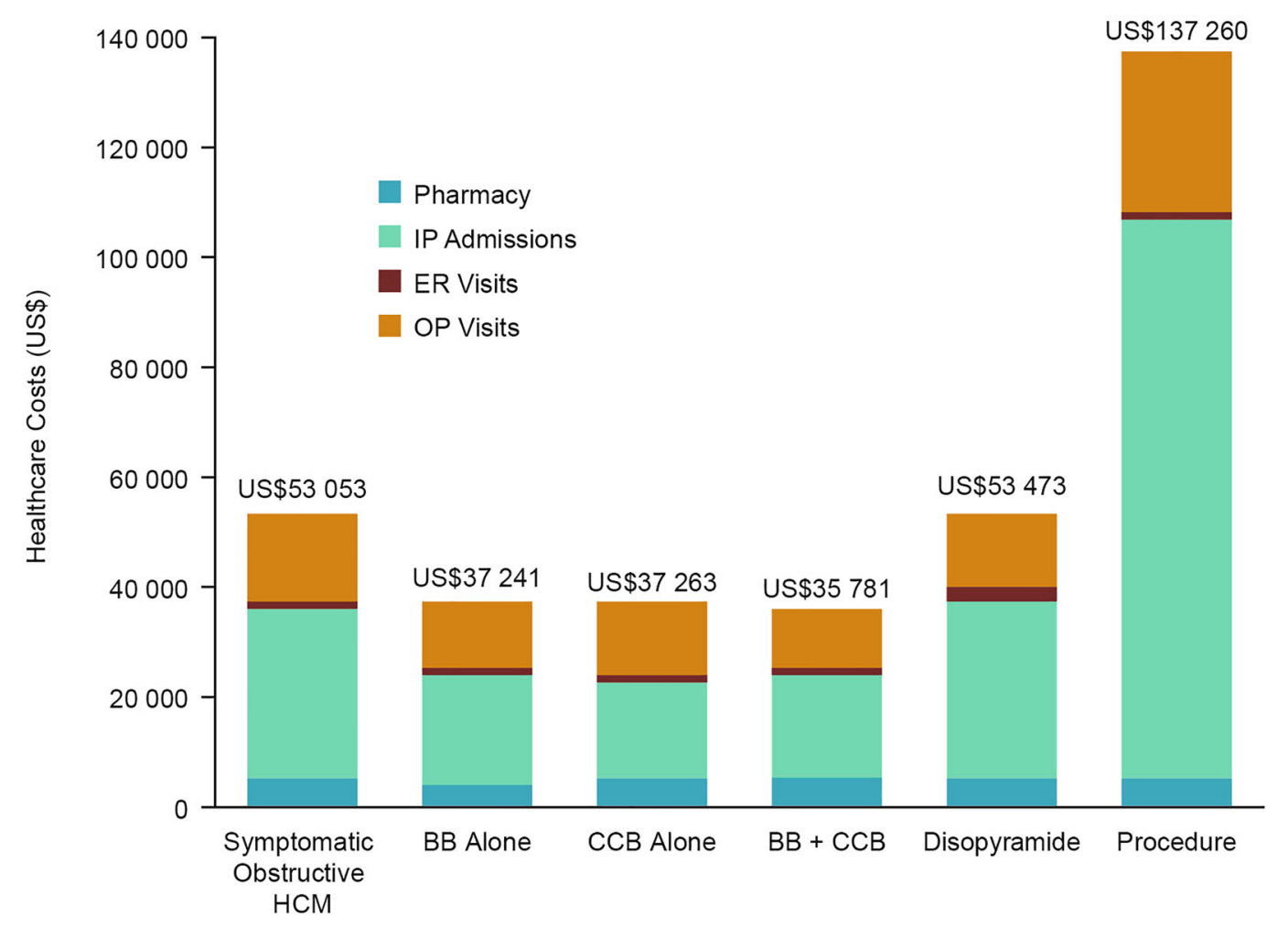

\begin{tabular}{|l|c|c|c|c|c|c|}
\hline \multicolumn{7}{|c|}{ Cost Breakdown (US\$) } \\
\hline Pharmacy & 4376 & 3783 & 4566 & 5248 & 4558 & 5201 \\
\hline IP Admissions & 31911 & 19122 & 17351 & 18134 & 32789 & 100998 \\
\hline ER Visits & 1194 & 1109 & 1017 & 1072 & 1821 & 1644 \\
\hline OP Visits & 15572 & 13227 & 14330 & 11327 & 14306 & 29417 \\
\hline Total & 53053 & 37241 & 37263 & 35781 & 53473 & 137260 \\
\hline
\end{tabular}

Fig. 5 All-cause healthcare costs during the study period. ER Emergency room, $I P$ inpatient, $O P$ outpatient

US\$37,263 ( \pm US\$89,680), and US\$35,781 ( \pm US\$73,442), respectively.

The Kaplan-Meier curves for the times from the index date to the first HCM-related inpatient visit and HCM-related ER visit, and SRT are shown in Fig. 6. Patients in the disopyramide group were most likely to undergo SRT within 1 year of initiation of treatment $(12.6 \%)$, followed by those in the $\mathrm{BB}+\mathrm{CCB}(6.9 \%)$, $\mathrm{CCB}$ alone $(5.8 \%)$, and $\mathrm{BB}$ alone $(5.0 \%)$ groups. Similar trends were observed for times to first HCM-related inpatient admission and first HCM-related ER visit.

\section{Index Treatment Changes}

Changes to the index treatment are summarized in Table 3 and Fig. 7. During the study period, 1807 patients $(43.8 \%)$ in the cohort that received pharmacotherapy had a treatment modification, with 1481 (35.9\%) discontinuing the index treatment, including 516 (12.5\%) who switched to a different treatment regimen, and $326(7.9 \%)$ adding a new class of treatment to the index treatment (augmentation). The mean (SD) adherence to the index pharmacotherapy was $74.0 \%( \pm 31.2 \%)$.

The disopyramide group had the highest rate of any treatment changes (56.3\%), followed by 

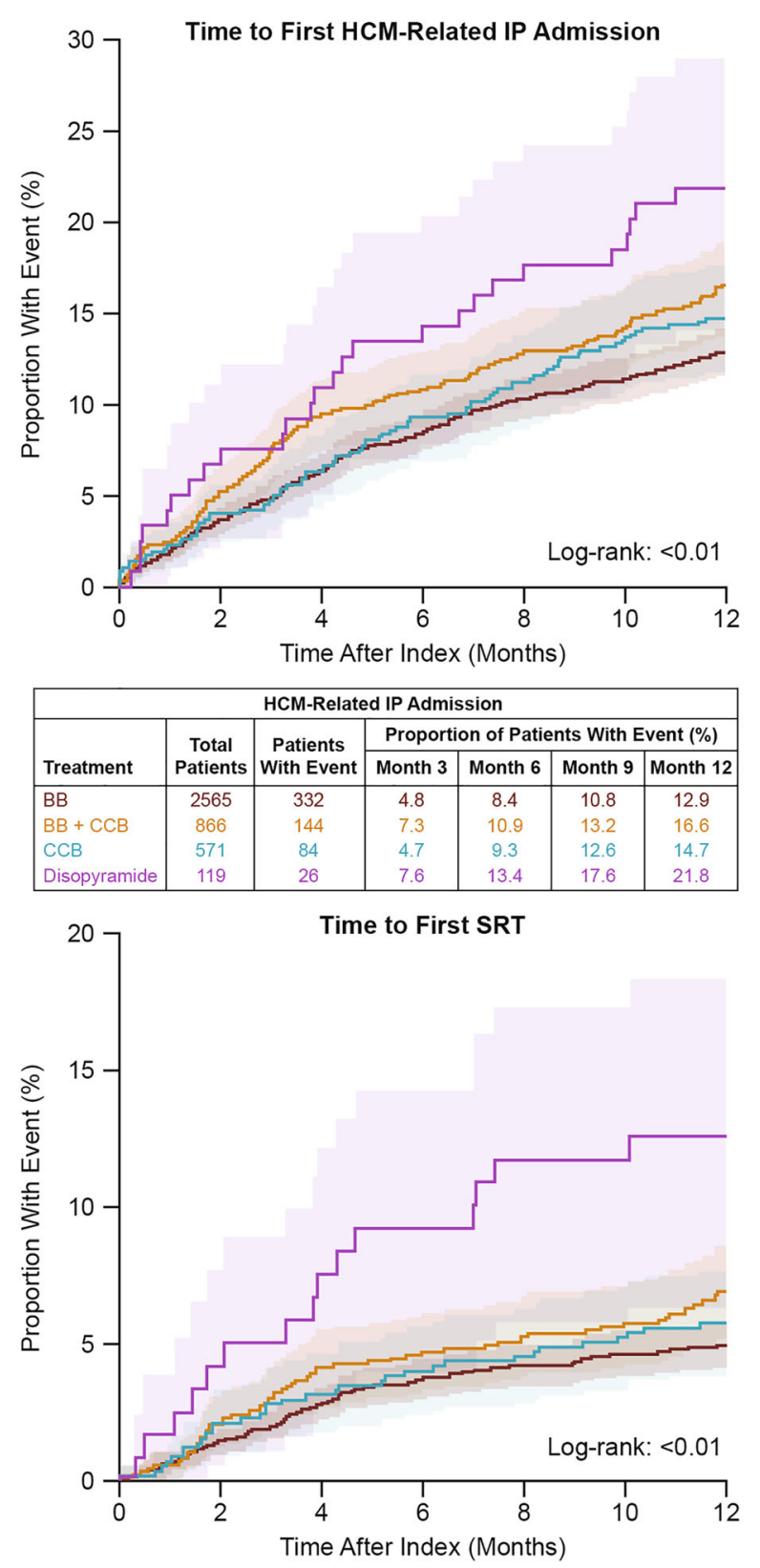

\begin{tabular}{|l|c|c|c|c|c|c|}
\hline \multicolumn{2}{|c|}{ SRT } \\
\hline & \multirow{2}{*}{ Treatment } & Total & Patients & \multicolumn{3}{|c|}{ Proportion of Patients With Event (\%) } \\
\cline { 4 - 7 } & Patients & With Event & Month 3 & Month 6 & Month 9 & Month 12 \\
\hline BB & $2564^{\text {a }}$ & 128 & 2.0 & 3.7 & 4.4 & 5.0 \\
BB + CCB & 866 & 60 & 3.1 & 4.7 & 5.4 & 6.9 \\
CCB & 571 & 33 & 2.8 & 4.0 & 4.9 & 5.8 \\
Disopyramide & 119 & 15 & 5.0 & 9.2 & 11.8 & 12.6 \\
\hline
\end{tabular}

Fig. 6 Kaplan-Meier analysis of time to the first HCMrelated healthcare resource utilization among patients with symptomatic obstructive HCM who received a
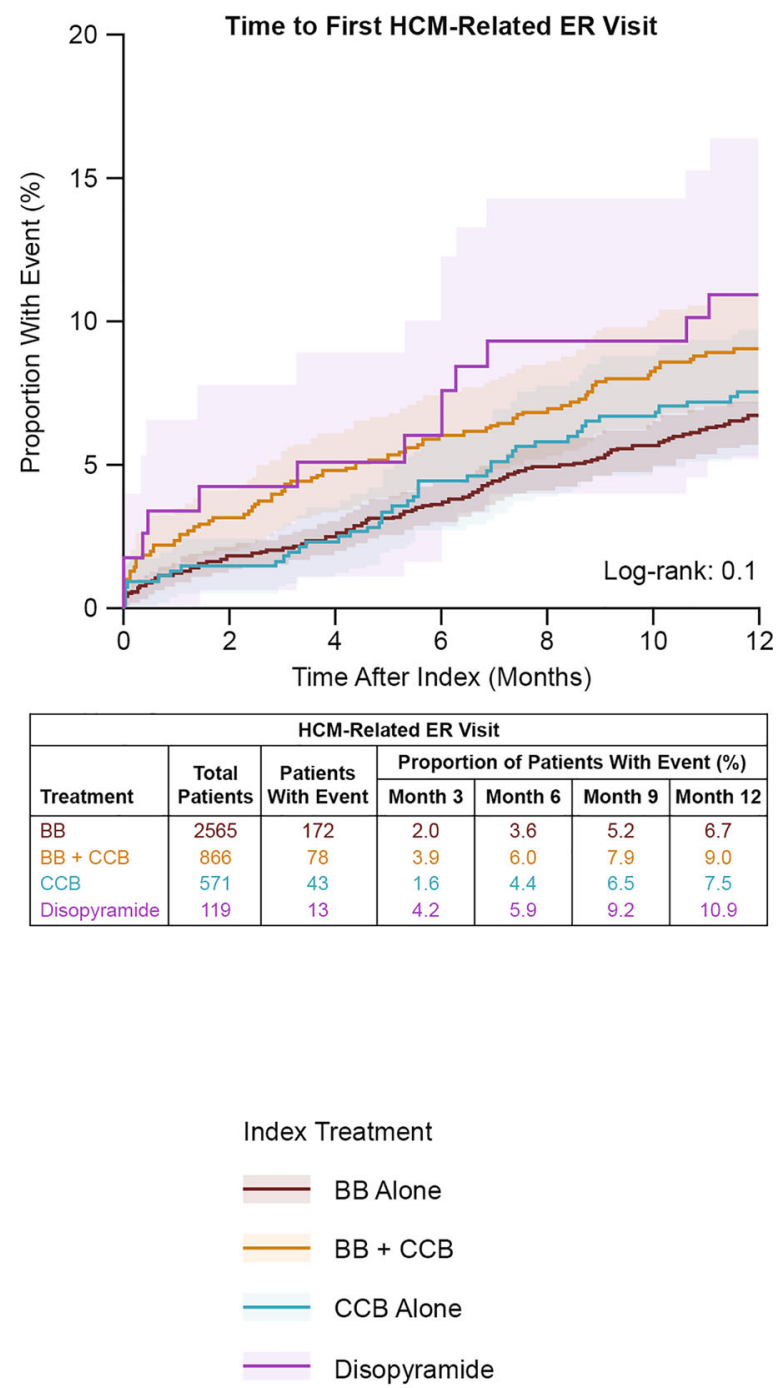

pharmacotherapy as the index treatment. ${ }^{a}$ One patient underwent SRT on the index date 
Table 3 Index treatment changes during the study period

\begin{tabular}{|c|c|c|c|c|c|}
\hline \multirow{2}{*}{$\begin{array}{l}\text { Index treatment } \\
\text { changes }\end{array}$} & \multirow{2}{*}{$\begin{array}{l}\text { Symptomatic obstructive } \\
\text { HCM }^{\mathrm{a}} \\
\text { received any } \\
\text { pharmacotherapy } \\
\text { as the index treatment } \\
(N=4121)\end{array}$} & \multicolumn{4}{|c|}{ Index treatment groups } \\
\hline & & $\begin{array}{l}\text { BB alone } \\
(n=2565)\end{array}$ & $\begin{array}{l}\text { CCB alone } \\
(n=866)\end{array}$ & $\begin{array}{l}\mathrm{BB}+\mathrm{CCB} \\
(n=571)\end{array}$ & $\begin{array}{l}\text { Disopyramide } \\
(n=119)\end{array}$ \\
\hline \multicolumn{6}{|c|}{ First change to the index treatment, $n(\%)$} \\
\hline Any change & $1807(43.8)$ & $1023(39.9)$ & $411(47.5)$ & $306(53.6)$ & $67(56.3)$ \\
\hline $\begin{array}{l}\text { Index treatment } \\
\text { discontinuation }\end{array}$ & $1481(35.9)$ & $821(32.0)$ & $399(46.1)$ & $206(36.1)$ & $55(46.2)$ \\
\hline Switching & $516(12.5)$ & $61(2.4)$ & $346(40.0)$ & $57(10.0)$ & $52(43.7)$ \\
\hline Augmentation & $326(7.9)$ & $202(7.9)$ & $12(1.4)$ & $100(17.5)$ & $12(10.1)$ \\
\hline \multicolumn{6}{|c|}{$\begin{array}{l}\text { Time from the index date to the first treatment change among patients with at least one treatment change during the } \\
12 \text {-month study period (months) }\end{array}$} \\
\hline Mean \pm SD & $4.0 \pm 2.7$ & $4.0 \pm 2.7$ & $4.1 \pm 2.6$ & $3.7 \pm 2.8$ & $4.3 \pm 3.1$ \\
\hline Median (IQR) & $3.0(1.6,5.9)$ & $3.0(1.7,5.9)$ & $3.5(1.9,6.0)$ & $3.0(1.2,5.6)$ & $3.2(1.2,6.6)$ \\
\hline
\end{tabular}

${ }^{a}$ Patients with obstructive HCM were classified as symptomatic if they met the following criteria: (1) had a medical claim for fatigue, chest pain, syncope, dyspnea, or palpitations during the baseline period; (2) had a medical claim for heart failure at any time prior to the index date; or (3) received pacemaker implantation or septal reduction therapy as the index treatment

the CCB alone (53.6\%), BB + CCB (47.5\%), and $\mathrm{BB}$ alone (39.9\%) groups. Among patients with any index treatment changes, the mean time from the index date to the first index treatment change was consistent: approximately 4 (median: 3) months across the index treatment groups.

\section{DISCUSSION}

This study used a large database of insurance claims to evaluate the economic burden and treatment patterns associated with existing treatments for symptomatic obstructive HCM. Based on our study design definition, almost two-thirds of patients with obstructive HCM in this study were classified as symptomatic. Of these, $64 \%$ were treated with $\mathrm{BB}$ or CCB monotherapy, and the remaining patients were treated with escalating therapies, such as combination $\mathrm{BB}+\mathrm{CCB}$ therapy, disopyramide, and procedures.

Ideally, treatments for symptomatic disease would stabilize or reduce the economic and clinical burden to patients and the healthcare system. Despite escalating treatment, however, patients with symptomatic obstructive HCM incurred considerable HRU and healthcare costs. More specifically, within the 1 year following index treatment initiation, these patients incurred over US $\$ 53,000$ in healthcare costs on average, and more than one-third experienced at least one inpatient admission or ER visit. The HRU and costs incurred by treated patients classified as having symptomatic obstructive HCM in the present cohort were generally higher than those of patients with other cardiovascular diseases, including atherosclerotic cardiovascular disease, coronary artery disease with angina, and a history of myocardial infarction [25-27]. For example, 

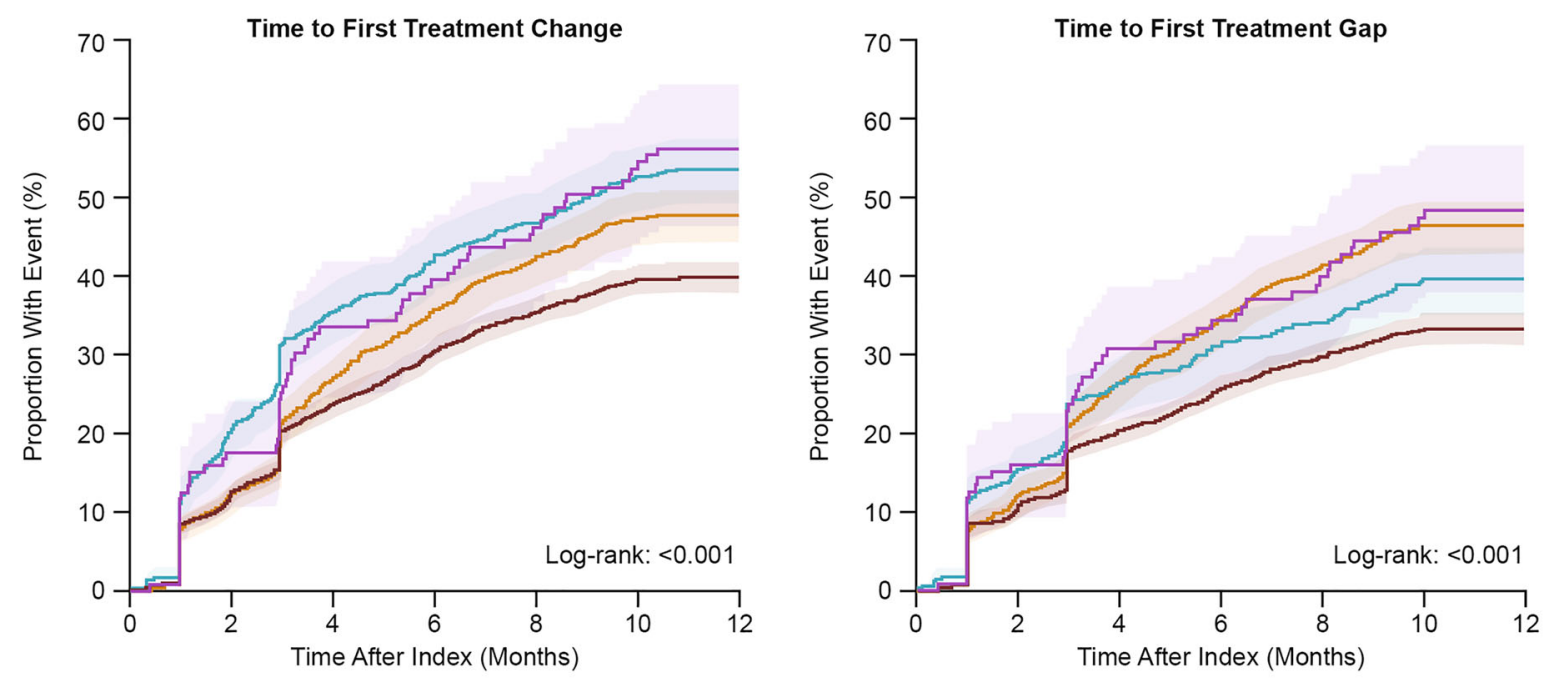

\begin{tabular}{|l|c|c|c|c|c|c|c|}
\hline \multicolumn{7}{|c|}{ Any Treatment Change } \\
\hline & Total & $\begin{array}{c}\text { Patients } \\
\text { With }\end{array}$ & $\begin{array}{c}\text { Event } \\
\text { (Month), }\end{array}$ & \multicolumn{3}{|c|}{ Proportion of Patients With Event (\%) } \\
\cline { 5 - 9 } Treatment & Patients & Event & $\mathbf{9 5 \%}$ Cl & Month 3 & Month 6 & Month 9 & Month 12 \\
\hline BB & 2565 & 1023 & Not reached & 20.3 & 30.4 & 37.5 & 39.9 \\
BB + CCB & 866 & 411 & $-(9.6,-)$ & 21.3 & 35.6 & 44.8 & 47.7 \\
CCB & 571 & 306 & $9(7.5,-)$ & 31.3 & 41.9 & 49.9 & 53.6 \\
Disopyramide & 119 & 67 & $8.6(6.5,-)$ & 25.2 & 39.5 & 50.4 & 56.3 \\
\hline
\end{tabular}

\begin{tabular}{|l|c|c|c|c|c|c|c|}
\hline \multicolumn{10}{|c|}{ Treatment Gap } \\
\hline & Total & $\begin{array}{c}\text { Patients } \\
\text { With }\end{array}$ & $\begin{array}{c}\text { Event } \\
\text { (Months), }\end{array}$ & \multicolumn{3}{|c|}{ Proportion of Patients With Event (\%) } \\
\cline { 6 - 9 } Treatment & Patients & Event & $\mathbf{9 5 \%}$ Cl & Month 3 & Month 6 & Month 9 & Month 12 \\
\hline BB & 2565 & 821 & Not reached & 17.8 & 25.6 & 31.5 & 33.2 \\
BB + CCB & 866 & 399 & Not reached & 20.9 & 34.7 & 43.8 & 46.4 \\
CCB & 571 & 206 & Not reached & 23.8 & 31.0 & 36.9 & 39.5 \\
Disopyramide & 119 & 55 & $-(8.1,-)$ & 23.7 & 34.2 & 44.5 & 48.3 \\
\hline
\end{tabular}
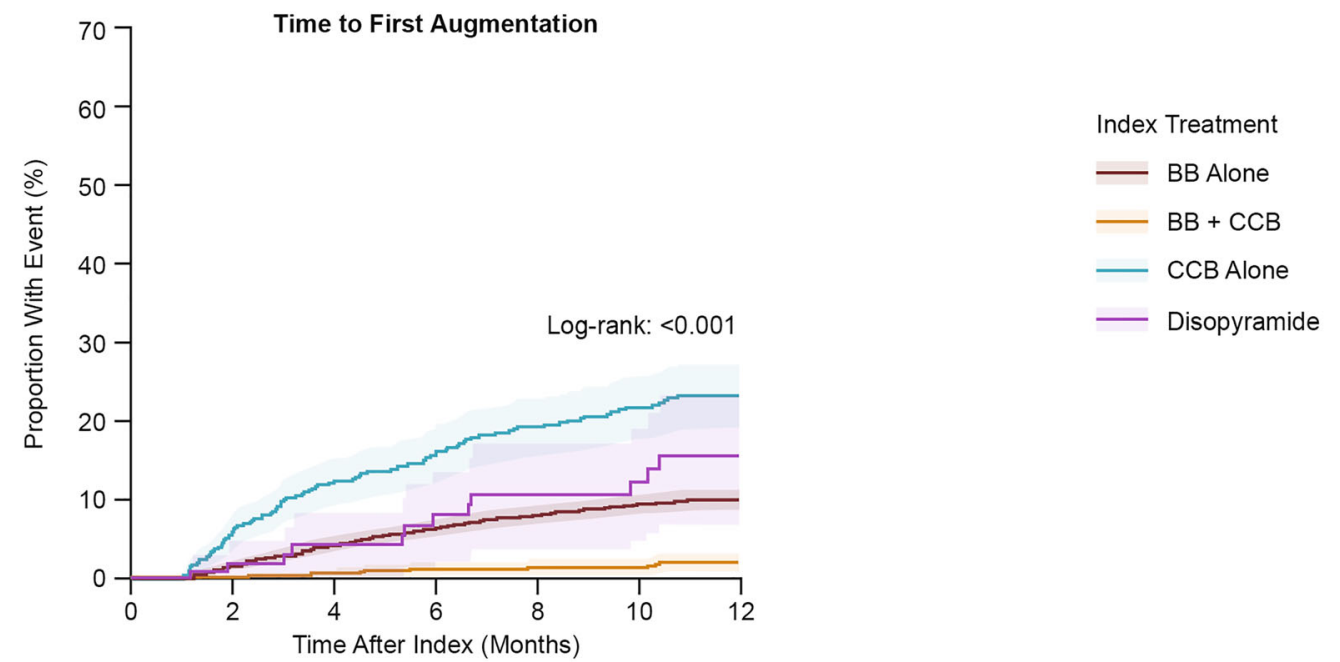

\begin{tabular}{|l|c|c|c|c|c|c|c|}
\hline \multicolumn{7}{|c|}{ Treatment Augmentation } \\
\hline & Total & $\begin{array}{c}\text { Patients } \\
\text { With }\end{array}$ & $\begin{array}{c}\text { Event } \\
\text { (Months), }\end{array}$ & \multicolumn{3}{|c|}{ Proportion of Patients With Event (\%) } \\
\cline { 5 - 9 } Treatment & Patients & Event & $\mathbf{9 5 \%}$ Cl & Month 3 & Month 6 & Month 9 & Month 12 \\
\hline BB & 2565 & 202 & Not reached & 3.0 & 6.4 & 8.8 & 10.0 \\
BB + CCB & 866 & 12 & Not reached & 0.4 & 1.2 & 1.4 & 2.0 \\
CCB & 571 & 100 & Not reached & 9.8 & 15.6 & 20.6 & 23.2 \\
Disopyramide & 119 & 12 & Not reached & 2.0 & 8.0 & 10.6 & 15.5 \\
\hline
\end{tabular}

Fig. 7 Kaplan-Meier analysis of time to treatment changes among patients with symptomatic obstructive hypertrophic cardiomyopathy who received a pharmacotherapy as the index treatment. $C I$ confidence interval 
Zhao et al. used a US employer-based claims database (2007-2011) to estimate HRU and healthcare costs during the first and second years following a diagnosis of coronary artery disease with diabetes, acute coronary syndromes, cerebrovascular atherosclerotic disease, or peripheral arterial disease among patients with high-risk atherosclerotic cardiovascular disease [25]. In that sample, $22.7 \%$ of patients had inpatient admissions, $33.4 \%$ had ER visits, and the annual mean total all-cause healthcare costs were approximately US\$19,000 within 1 year of follow-up. In addition, prior research has suggested that treatments for patients classified as having symptomatic obstructive HCM did not reduce HRU or costs. Jain et al., using the same database as this study but with a different design and cohorts, evaluated the economic burden of symptomatic obstructive HCM among treated and untreated patients [17]. The study showed the same hospitalization rate and frequency as our study, with a 1-year hospitalization rate of $38 \%$ and a mean of 3.7 inpatient days per patient-year. The annual healthcare costs were estimated at US $\$ 43,586$ among treated and untreated patients, almost US $\$ 10,000$ lower than the healthcare costs in treated patients in our study. Although the two studies are not directly comparable owing to differences in the cohorts included, the results suggest that HRU and costs remain elevated despite current treatments for symptomatic obstructive HCM.

The present results suggest that the economic burden increased as patients progressed through escalating lines of therapies. For example, patients treated with disopyramide or procedures incurred 1.4- and 3.7-fold higher healthcare costs, respectively, than those treated with BBs and/or CCBs. Escalating pharmacological therapies did not appear to reduce disease burden. Both the BB + CCB and disopyramide groups had higher HRU across all types than patients in the $\mathrm{BB}$ or $\mathrm{CCB}$ monotherapy groups. Procedures may reduce symptom burden if performed at experienced treatment centers [18-20]. However, they are associated with high treatment costs related to the procedure itself.
In addition to the high economic burden, this study also showed that treatment adherence was a challenge for almost half of the patients with symptomatic obstructive HCM. Prior research on treatment patterns for symptomatic obstructive HCM is limited. A singlecenter study reported that $58 \%$ and $4 \%$ of those with symptomatic HCM were treated with BB monotherapy and disopyramide, respectively [28], which is similar to our findings. An evaluation of treatment change for symptomatic obstructive HCM can lead to improved understanding of the burden associated with pharmacological treatments. Our results indicated that approximately one-third of patients in the $\mathrm{BB}$ alone group, over one-third of patients in the CCB alone group, and almost half of patients in the $\mathrm{BB}+\mathrm{CCB}$ group and the disopyramide group discontinued the index treatment, potentially suggesting poor effectiveness at controlling HCM symptoms and/or limited tolerability. In addition, approximately $8 \%$ of patients in the study population augmented their treatment, which again may indicate a lack of effectiveness of the current pharmacotherapies at controlling symptoms in obstructive HCM. Previous literature has confirmed that a low adherence is associated with poor effectiveness among patients with cardiovascular diseases $[29,30]$. The high rate of treatment change observed in the current study demonstrated the unmet medical need associated with symptomatic obstructive HCM.

Despite this clear unmet treatment need, the burden of obstructive HCM is not fully understood. Most prior studies on the burden related to treatments for obstructive HCM have focused on economic outcomes following a specific procedure. For example, Sun et al. assessed the 2-year post-procedural HRU and healthcare costs associated with SRT and estimated the hospital readmission rate to be $40 \%$ and median annual healthcare costs to be close to US $\$ 20,000$ [31]. The current study, using a large US claims database, includes both pharmacological treatments and procedures, which enhances our understanding of the overall treatment pattern in patients with symptomatic obstructive HCM, as well as the economic burden among treated patients. The findings show 
that symptomatic obstructive HCM, even with escalating therapies, poses an increasing economic burden on patients and healthcare systems, indicating a failure of these therapies to halt the progression of disease and symptoms. Overall, our results suggest an unmet economic burden associated with the existing treatments for symptomatic obstructive HCM.

\section{Limitations}

This study is subject to several limitations, some of which are common across claims database analyses. First, obstructive HCM diagnoses, symptoms, and comorbidities were identified based on ICD-9-CM and ICD-10-CM diagnosis codes. A diagnosis code on a medical claim is not a confirmation that the patient had the diagnosis of disease because the code may represent a rule-out diagnosis or may be recorded incorrectly. This limitation was mitigated by requiring eligible patients to have at least two claims with diagnosis codes for HCM or one claim with a diagnosis code for HCM plus one claim for SRT. It is also important to note that generic codes, such as codes for "other cardiomyopathy" and "unspecified cardiomyopathy," which may be used for HCM, were not included in this study. Second, there are no existing diagnosis codes or well-established algorithms to identify symptomatic obstructive HCM in claims databases. In this study, a combination of symptoms, comorbidities, and procedures was used to identify symptomatic obstructive HCM. Because not all symptoms were captured in the claims database and some symptoms might have been due to comorbidities, the actual proportion of patients with symptomatic obstructive HCM may be different to that estimated in our study. Third, the identification of treatment initiation was based on pharmacy prescription fills in the claims database, and measures of treatment duration were based on days of supply. This approach may not represent how the treatments were actually taken by patients. Changes to the index treatment were assessed during the first year after treatment initiation. Future research could focus on long-term treatment patterns and outcomes to improve understanding of the treatment and disease trajectories of symptomatic obstructive HCM. Finally, given that this study was conducted in a commercially insured and Medicare Supplemental patient sample, its findings may not be generalizable to other patient populations (Medicaid and the uninsured).

\section{CONCLUSIONS}

This study provides real-world evidence that, in patients with symptomatic obstructive HCM, HRU and healthcare costs increased as therapy escalated. One-third of treated patients with symptomatic obstructive HCM required escalating therapies $(\mathrm{BB}+\mathrm{CCB}$, disopyramide, or procedures), which were themselves associated with even higher clinical and economic burdens. In addition, a high proportion of patients augmented, switched, or discontinued their medical therapies. These patients experience considerable burden despite existing treatments.

\section{ACKNOWLEDGEMENTS}

Funding. Funding for this study and the Journal's Rapid Service Fee was provided by MyoKardia, Inc., a wholly owned subsidiary of Bristol Myers Squibb.

Editorial Assistance. Editorial assistance was provided by Shelley Batts, $\mathrm{PhD}$, an employee of Analysis Group, Inc. Support for this assistance was funded by MyoKardia, Inc., a wholly owned subsidiary of Bristol Myers Squibb.

Authorship. All named authors meet the International Committee of Medical Journal Editors (ICMJE) criteria for authorship for this article, take responsibility for the integrity of the work as a whole, and have given their approval for this version to be published. Megan Sutton current affiliation: Renovacor, Boston, MA, USA. 
Author Contributions. All the authors participated in the conception and design of the study, and in the analysis and interpretation of data. All the authors participated in the preparation of the manuscript.

Disclosures. Megan B Sutton was an employee of MyoKardia, Inc., a wholly owned subsidiary of Bristol Myers Squibb. Jennifer T. Fine is an employee of MyoKardia, Inc., a wholly owned subsidiary of Bristol Myers Squibb, and holds stock/options. Wei Gao and Jipan Xie are employees of Analysis Group, Inc., which has received consulting fees from Bristol Myers Squibb and MyoKardia, Inc. Anjali $\mathrm{T}$ Owens reports consulting for Cytokinetics and MyoKardia/Bristol Myers Squibb. Srihari S Naidu is a consultant and serves on advisory boards for Bristol Myers Squibb and Cytokinetics; he is on the Executive Committee of the VALOR trial for Bristol Myers Squibb. Nihar R Desai works under contract with the Centers for Medicare and Medicaid Services to develop and maintain performance measures used for public reporting and pay for performance programs; he reports research grants and/or consulting for Amgen, AstraZeneca, Boehringer Ingelheim, Cytokinetics, MyoKardia, Inc., Novartis, scPharmaceuticals, and Vifor Pharma.

Compliance with Ethics Guidelines. This article is based on information from an existing database and does not contain any new studies with human participants or animals performed by any of the authors.

Data Availability. The datasets generated during and/or analyzed during the current study are available from the corresponding author on reasonable request. BMS policy on data sharing may be found at https://www.bms. com/researchers-and-partners/independentresearch/data-sharing-request-process.html.

Open Access. This article is licensed under a Creative Commons Attribution-NonCommercial 4.0 International License, which permits any non-commercial use, sharing, adaptation, distribution and reproduction in any medium or format, as long as you give appropriate credit to the original author(s) and the source, provide a link to the Creative Commons licence, and indicate if changes were made. The images or other third party material in this article are included in the article's Creative Commons licence, unless indicated otherwise in a credit line to the material. If material is not included in the article's Creative Commons licence and your intended use is not permitted by statutory regulation or exceeds the permitted use, you will need to obtain permission directly from the copyright holder. To view a copy of this licence, visit http://creativecommons.org/licenses/by$\mathrm{nc} / 4.0 /$.

\section{REFERENCES}

1. Elliott PM, Anastasakis A, Borger MA, et al. 2014 ESC guidelines on diagnosis and management of hypertrophic cardiomyopathy: the task force for the diagnosis and management of hypertrophic cardiomyopathy of the European Society of Cardiology (ESC). Eur Heart J. 2014;35:2733-79.

2. Ommen SR, Mital S, Burke MA, et al. 2020 AHA/ ACC guideline for the diagnosis and treatment of patients with hypertrophic cardiomyopathy: a report of the American College of Cardiology/ American Heart Association Joint Committee on Clinical Practice Guidelines. J Am Coll Cardiol. 2020;76:e159-240.

3. Marian AJ, Braunwald E. Hypertrophic cardiomyopathy: genetics, pathogenesis, clinical manifestations, diagnosis, and therapy. Circ Res. 2017;121: 749-70.

4. Gersh BJ, Maron BJ, Bonow RO, et al. 2011 ACCF/ AHA guideline for the diagnosis and treatment of hypertrophic cardiomyopathy: a report of the American College of Cardiology Foundation/ American Heart Association Task Force on Practice Guidelines. J Am Coll Cardiol. 2011;58:e212-60.

5. Ammirati E, Contri R, Coppini R, Cecchi F, Frigerio M, Olivotto I. Pharmacological treatment of hypertrophic cardiomyopathy: current practice and novel perspectives. Eur J Heart Fail. 2016;18: 1106-18.

6. Maron BJ, Gardin JM, Flack JM, Gidding SS, Kurosaki TT, Bild DE. Prevalence of hypertrophic cardiomyopathy in a general population of young adults. Echocardiographic analysis of 4111 subjects in the CARDIA study. Coronary aArtery Risk 
Development in (Young) Adults. Circulation. 1995;92:785-9.

7. Semsarian C, Ingles J, Maron MS, Maron BJ. New perspectives on the prevalence of hypertrophic cardiomyopathy. J Am Coll Cardiol. 2015;65: 1249-54.

8. Heitner SB, Jacoby D, Lester SJ, et al. Mavacamten treatment for obstructive hypertrophic cardiomyopathy: a clinical trial. Ann Intern Med. 2019;170: 741-8.

9. Maron MS, Olivotto I, Zenovich AG, et al. Hypertrophic cardiomyopathy is predominantly a disease of left ventricular outflow tract obstruction. Circulation. 2006;114:2232-9.

10. Lu DY, Pozios I, Haileselassie B, et al. Clinical outcomes in patients with nonobstructive, labile, and obstructive hypertrophic cardiomyopathy. J Am Heart Assoc. 2018;7:e006657.

11. Maron BJ. Clinical course and management of hypertrophic cardiomyopathy. $\mathrm{N}$ Engl J Med. 2018;379:655-68.

12. Finocchiaro G, Magavern E, Sinagra G, et al. Impact of demographic features, lifestyle, and comorbidities on the clinical expression of hypertrophic cardiomyopathy. J Am Heart Assoc. 2017;6:e007161.

13. Cox S, O'Donoghue AC, McKenna WJ, Steptoe A. Health related quality of life and psychological wellbeing in patients with hypertrophic cardiomyopathy. Heart. 1997;78:182-7.

14. Huff CM, Turer AT, Wang A. Correlations between physician-perceived functional status, patient-perceived health status, and cardiopulmonary exercise results in hypertrophic cardiomyopathy. Qual Life Res. 2013;22:647-52.

15. Luiten RC, Ormond K, Post L, Asif IM, Wheeler MT, Caleshu C. Exercise restrictions trigger psychological difficulty in active and athletic adults with hypertrophic cardiomyopathy. Open Heart. 2016;3: e000488.

16. Magnusson P, Morner S, Gadler F, Karlsson J. Health-related quality of life in hypertrophic cardiomyopathy patients with implantable defibrillators. Health Qual Life Outcomes. 2016;14:62.

17. Jain SS, Li SS, Xie J, et al. Clinical and economic burden of obstructive hypertrophic cardiomyopathy in the US. J Med Econ. 2021;24:1115-23.

18. Kim LK, Swaminathan RV, Looser P, et al. Hospital volume outcomes after septal myectomy and alcohol septal ablation for treatment of obstructive hypertrophic cardiomyopathy: US nationwide inpatient database, 2003-2011. JAMA Cardiol. 2016;1:324-32.

19. Liebregts M, Vriesendorp PA, Mahmoodi BK, Schinkel AF, Michels M, ten Berg JM. A systematic review and meta-analysis of long-term outcomes after septal reduction therapy in patients with hypertrophic cardiomyopathy. JACC Heart Fail. 2015;3:896-905.

20. Wells SB, Rowin E, Bhatt V, Maron M, Maron BJ. Racial differences in clinical course and outcome of patients with hypertrophic cardiomyopathy. Poster presented at ACC 2018; 10-12 March 2018; Orlando. Poster number 1238-091.

21. Brignole M, Auricchio A, Baron-Esquivias G, et al. 2013 ESC Guidelines on cardiac pacing and cardiac resynchronization therapy: the Task Force on cardiac pacing and resynchronization therapy of the European Society of Cardiology (ESC). Developed in collaboration with the European Heart Rhythm Association (EHRA). Eur Heart J. 2013;34:2281-329.

22. IBM Watson Health. IBM MarketScan Research Databases for Health Services Researchers [White Paper]. 2019. https://www.ibm.com/downloads/ cas/OWZWJ0QO. Accessed Dec 2021.

23. Charlson ME, Pompei P, Ales KL, MacKenzie CR. A new method of classifying prognostic comorbidity in longitudinal studies: development and validation. J Chronic Dis. 1987;40:373-83.

24. Deyo RA, Cherkin DC, Ciol MA. Adapting a clinical comorbidity index for use with ICD-9-CM administrative databases. J Clin Epidemiol. 1992;45: 613-9.

25. Zhao Z, Zhu Y, Fang Y, Ye W, McCollam P. Healthcare resource utilization and costs in working-age patients with high-risk atherosclerotic cardiovascular disease: findings from a multi-employer claims database. J Med Econ. 2015;18:655-65.

26. Yang E, Stokes M, Johansson S, et al. Clinical and economic outcomes among elderly myocardial infarction survivors in the USA. Cardiovasc Ther. 2016;34:450-9.

27. Kempf J, Buysman E, Brixner D. Health resource utilization and direct costs associated with angina for patients with coronary artery disease in a US managed care setting. Am Health Drug Benefits. 2011;4:353-61.

28. Maron BJ, Casey SA, Poliac LC, Gohman TE, Almquist AK, Aeppli DM. Clinical course of hypertrophic cardiomyopathy in a regional US cohort. JAMA. 1999;281:650-5. 
29. Chowdhury R, Khan H, Heydon E, et al. Adherence to cardiovascular therapy: a meta-analysis of prevalence and clinical consequences. Eur Heart J. 2013;34:2940-8.

30. Chen S-T, Huang S-T, Shau W-Y, et al. Long-term statin adherence in patients after hospital discharge for new onset of atherosclerotic cardiovascular disease: a population-based study of real world prescriptions in Taiwan. BMC Cardiovasc Disord. 2019;19:1-13.

31. Sun D, Schaff HV, Houten HKV, et al. Health care utilization and costs of surgical septal myectomy and alcohol septal ablation for obstructive hypertrophic cardiomyopathy. Presented at the Western Thoracic Surgical Association 46th Annual Meeting; 24-27 June 2020; Vail, Colorado. Abstract US2020. 